\title{
Detection rate of crossing vessels in pediatric hydronephrosis: Transperitoneal laparoscopy versus open lumbotomy
}

\author{
Marcin Polok ${ }^{A-D}$, Dominika Borselle ${ }^{B, C}$, Krystian Toczewski ${ }^{B, C}$, Wojciech Apoznański ${ }^{E, F}$, Dariusz Patkowski ${ }^{C, E, F}$ \\ Department of Pediatric Surgery and Urology, Wroclaw Medical University, Poland \\ A - research concept and design; $B$ - collection and/or assembly of data; $C$ - data analysis and interpretation; \\ $\mathrm{D}$ - writing the article; $\mathrm{E}$ - critical revision of the article; $\mathrm{F}$ - final approval of the article
}

Address for correspondence

Marcin Polok

E-mail: polok.m@gmail.com

Funding sources

None declared

Conflict of interest

None declared

Received on August 15, 2018

Reviewed on December 13, 2018

Accepted on February 18, 2019

Published online on March 27, 2019

Cite as

Polok M, Borselle D, Toczewski K, Apoznański W, Patkowski D. Detection rate of crossing vessels in pediatric hydronephrosis - transperitoneal laparoscopy versus open lumbotomy. Adv Clin Exp Med. 2019;28(11):1507-1511.

doi:10.17219/acem/104528

DOI

10.17219/acem/104528

Copyright

Copyright by Author(s)

This is an article distributed under the terms of the

Creative Commons Attribution Non-Commercial License

(http://creativecommons.org/licenses/by-nc-nd/4.0/)

\begin{abstract}
Background. A bundle of crossing vessels (CV) supplying the lower pole of the kidney and causing mechanical obstruction of the ureteropelvic junction (UPJ) has been the subject of many discussions. During pyeloplasty, it is possible to overlook the CV. This may result in recurrent dilatation of the kidney and the need for re-surgery.

Objectives. To compare the detection rate of (V in UPJ obstruction (UPJO) depending on the operational access applied (transperitoneal laparoscopy (LAP) vs open lumbotomy (OPEN)). Assessment of features that could indicate the presence of $\mathrm{CV}$.

Material and methods. Two hundred and forty-six pediatric pyeloplasties were performed between January 2006 and July 2017 in the Department of Pediatric Surgery and Urology at the Wroclaw Medical University, Poland - 111 out of them by LAP and 135 by OPEN, on 98 girls and 148 boys. A retrospective analysis of the patient records for the detection of $C V$ and characteristics of the $C V$ before surgery was performed.

Results. Intraoperative CV causing obstruction of the UPJ in the LAP group were recognized in $34.2 \%$ ( $n=38)$ of the patients, and within the OPEN group in 12.5\% ( $n=17)(p<0.0001) ; 90 \%(n=27)$ of patients with the diagnosed CV did not show congenital hydronephrosis. In $68 \%(n=21)$ of the patients there were cases of recurrent renal colic. The presence of $\mathrm{C} V$ was suspected in $7.2 \%$ of kidney ultrasounds and in $12.5 \%$ in computed tomography (CT) urograms.
\end{abstract}

Conclusions. The detection rate of CV in UPJO is statistically higher in LAP access than in open retroperitoneal lumbotomy. The distinguishing features of patients with CV are the lack of prenatal diagnosis for hydronephrosis and the presence of pain in the lumbar region.

Key words: hydronephrosis, ureteropelvic junction obstruction, pyeloplasty, vascular hitch, crossing vessels 


\section{Introduction}

In the pathogenesis of pediatric hydronephrosis (ureteropelvic junction obstruction - UPJO), we can distinguish intrinsic and extrinsic factors. ${ }^{1}$ The most frequently mentioned intrinsic factors are the stenosis of the ureteropelvic junction (UPJ), fibroepithelial polyps and ureteral valves, and impaired number and expression of Cayal-like interstitial cells. ${ }^{1-3}$ Among the extrinsic factors, crossing vessels $(\mathrm{CV})$ are the first mentioned, causing obstruction of the UPJ. Less-frequently given reasons for UPJO include high abduction, ureteral twist or adhesions in the retroperitoneal space. ${ }^{4-6}$

A bundle of CV supplying the lower pole of the kidney and causing mechanical obstruction of the UPJ has been the subject of many discussions. Particularly debatable aspects include the detection rate and a method for dealing with recognized $\mathrm{CV}$ and the accompanying hydronephrosis. During pyeloplasty, in the cases of both the open and laparoscopic type, it is possible to overlook CV. This may result in recurrent dilatation of the kidney and (in some cases) also pain symptoms despite surgical treatment. It is important for a surgeon to be aware of the presence of $\mathrm{CV}$ and to remain vigilant when preparing the UPJ.

Crossing vessels are much more common in older children and adults, with no history of congenital hydronephrosis (prenatally diagnosed). ${ }^{7}$ Moreover, characteristic features are colic and paroxysmal pains in the lumbar region. Subsequent ultrasound examinations may significantly differ in the aspect of the sizes of the pelvicalyceal system of sick kidney. These patients should be suspected of having an additional vascular bundle. In such cases, it is important not to overlook the CV during the surgery and to apply an appropriate surgical technique.

\section{Objectives}

The study was aimed at comparing the detection rate of CV in UPJO depending on the operational access applied (transperitoneal laparoscopy vs open lumbotomy). Additionally, we assessed the features that could indicate the presence of $\mathrm{CV}$.

\section{Material and methods}

A retrospective analysis of the documentation of patients operated on from January 2006 to July 2017 in the Department of Pediatric Surgery and Urology at the Wroclaw Medical University, Poland, was carried out, where 246 pyeloplasties were performed on 98 girls and 148 boys. In the qualification for hydronephrosis surgery, renal ultrasound and renoscintigraphy were performed in all the patients. In dubious cases, computed urotomography was additionally performed. The patients were divided into
2 groups: LAP - patients operated on using a laparoscopic technique with transperitoneal access, $\mathrm{n}=111$, and OPEN - patients operated on using an open technique from a retroperitoneal approach, $\mathrm{n}=135$. Fisher's exact test with Wessa software (wessa.net).

\section{Results}

A summary of patients operated on with the different surgical techniques depending on access - laparoscopy or open technique - is presented in Table 1.

Additional CV before surgery were suspected in $7.2 \%$ of the patients in the ultrasound of the kidney and in $12.5 \%$ in computed urotomography. Intraoperative CV causing obstruction of the UPJ in the LAP group were diagnosed in $34.2 \%(\mathrm{n}=38)$, and in the OPEN group in $12.5 \%(\mathrm{n}=17)$ (Table 2$)(\mathrm{p}<0.0001)$. Two patients from the LAP group had previously undergone an unsuccessful surgery with the open retroperitoneal approach using the AndersonHynes method. In these cases, the presence of CV was not recognized intraoperatively, however, they were found in the second, laparoscopic surgery.

The number (rate) of laparoscopic hydronephrosis operations grew over time, reached $23.6 \%$ in first 3 years of this study and amounted $61.2 \%$ in the last 3 years. The rate of open surgeries simultaneously decreased.

A decision on the selection of the surgical technique after the diagnosis of the CV was made intraoperatively

Table 1. Summary of all patients operated on with open techniques (OPEN group) and laparoscopic techniques (LAP group) with division into various surgical techniques

\begin{tabular}{|l|c|c|}
\multicolumn{1}{|c|}{ Surgical technique } & LAP & OPEN \\
\hline All surgical techniques & 111 & 135 \\
\hline Anderson-Hynes & 78 & 127 \\
\hline Fenger & 4 & 3 \\
\hline Foley (Y-V Plasty) & 2 & 2 \\
\hline Hellström, mod. Chapman & 26 & 2 \\
\hline Other & 1 & 1 \\
\hline
\end{tabular}

Table 2. Summary of patients with diagnosed crossing vessels (CV) depending on the surgical access (LAP group - laparoscopy and OPEN group - classical surgery)

\begin{tabular}{|l|c|c|}
\multicolumn{1}{|c|}{ Variable } & LAP & OPEN \\
\hline Number of patients with CV & $38 / 111(34.2 \%)$ & $17 / 135(12.5 \%)$ \\
\hline Median age [years] & 6 & 5.5 \\
\hline Sex & M-25 (65.8\%) & M-9 (52.9\%) \\
\hline $\begin{array}{l}\text { Anderson-Hynes + } \\
\text { posterior translocation of CV }\end{array}$ & $14(36.1 \%)$ \\
$\begin{array}{l}\text { Hellström, mod. Chapman } \\
\text { (cephalad translocation } \\
\text { of CV) }\end{array}$ & $24(63.2 \%)$ & $15(88.2 \%)$ \\
\hline
\end{tabular}


Table 3. Characteristic features of hydronephrosis patients with diagnosed crossing vessels (CV)

\begin{tabular}{|c|c|c|c|}
\hline $\begin{array}{l}\text { Hydronephrosis } \\
\text { diagnosed antenatally }\end{array}$ & yes - 10\% (3) & no $-90 \%(27)$ & n.d. -25 \\
\hline $\begin{array}{l}\text { Recurrent pain/renal } \\
\text { colic }\end{array}$ & yes $-68 \%(21)$ & no $-32 \%(10)$ & n.d. -24 \\
\hline $\begin{array}{l}\text { Suspected CV } \\
\text { in ultrasound }\end{array}$ & yes - $4(7.2 \%)$ & no -51 & - \\
\hline $\begin{array}{l}\text { Suspected CV in CT } \\
\text { examination (Uro-CT) }\end{array}$ & yes - 1 (12.5\%) & no -7 & - \\
\hline Median age [years] & 5.75 & - & - \\
\hline
\end{tabular}

n.d. - no data; Uro-CT - urotomography.

on the basis of the UPJ anatomy and the entire disease picture. Data of the patients with CV depending on the surgical access is presented in Table 2. Data regarding the interview and imaging tests is given in Table 3 . The age of patients in individual groups was also analyzed, which is given in Table 2. Diagram showing the age of patients with $\mathrm{CV}$ at the time of surgery is presented in Fig. 1. Crossing vessels were not revealed in any patient under 1 year of age. The median age of patients with CV did not differ from the median age of patients without $\mathrm{CV}$ and it was 5.75 years. Dilatation of the renal pelvis in the anteriorposterior (AP) diameter before surgery in the group without CV was $30 \mathrm{~mm}$ (median) (from 15 to 55), and also $30 \mathrm{~mm}$ in the group with CV (from 13 to 70 ) ( $\mathrm{p}>0.05$ ).

A certain limitation to our study is the fact that some surgeons operated on the patients with the use of a laparoscopic technique and others with an open technique. Moreover, the study was performed retrospectively.

\section{Discussion}

The most common extrinsic factor of UPJO is the presence of $\mathrm{CV}^{1,4,5,7}$ In the literature, they are described as an artery or an artery and a vein supplying the lower pole of the kidney. Localized at the height of the UPJ, they can cause mechanical obstruction and the occurrence of a symptomatic hydronephrosis (Fig. 2). In a typical course of UPJO with the presence of CV in the history, recurring pain in the lumbar and abdominal region frequently occurs. ${ }^{7}$ In the analyzed material, the symptoms of renal colic, nausea and vomiting were the dominant symptoms in patients with CV. As many as $68 \%$ of our patients presented with CV. According to the literature, in most cases, children with CV in a prenatal and neonatal interview do not have the dilatation of the kidney. ${ }^{1,7}$ This variant of the disease is even referred to by some researchers as "adult hydronephrosis". We obtained very similar results in our material. The vast majority of the patients - as much as $90 \%$ in ultrasound, both prenatal and in the neonatalinfancy period - did not show kidney dilatation. Furthermore, in patients with $\mathrm{CV}$, in subsequent ultrasound scans,

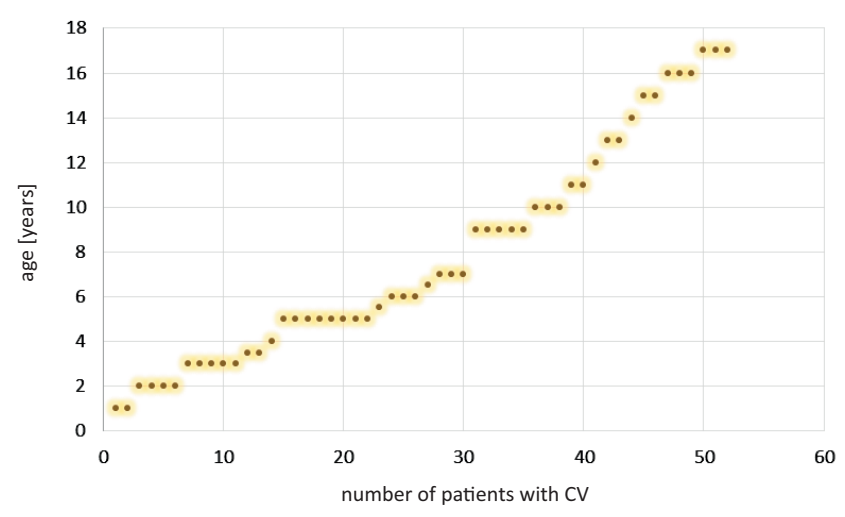

Fig. 1. Diagram showing the age of patients with crossing vessels (CV) at the time of surgery

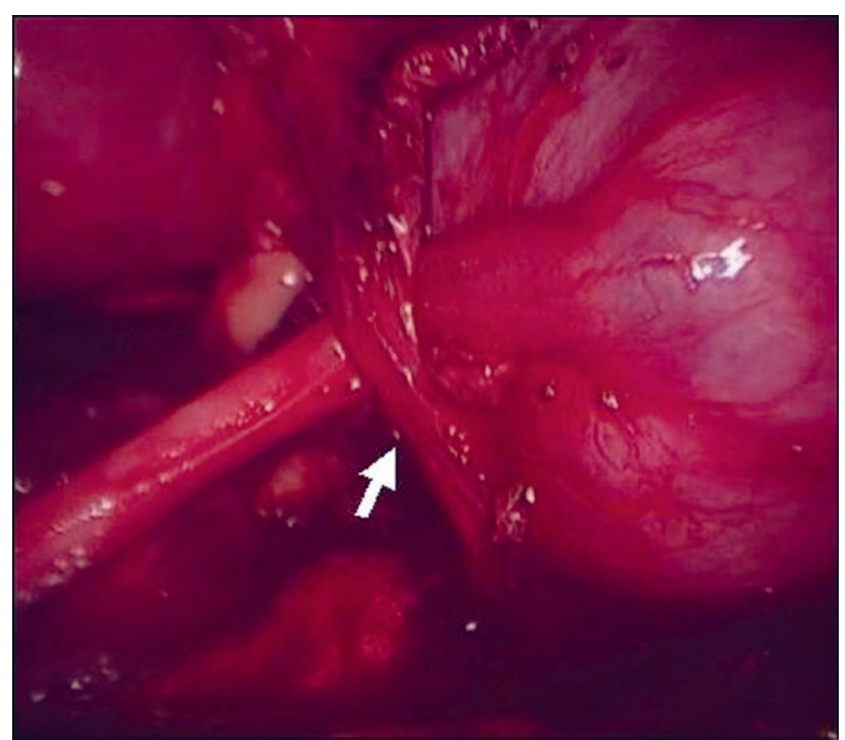

Fig. 2. Intraoperative image during laparoscopic pyeloplasty. Crossing vessel causing obstruction of the ureteropelvic junction (UPJ), marked by arrow

the sizes of the kidney pelvis may differ significantly from one another. This is due to the fact that the UPJ obstruction is the so-called "permeable obstruction".

The renal pelvis most often in the case of $\mathrm{CV}$ is not very dilatated (less than $30 \mathrm{~mm}$ in the AP dimension), and it can be located deeply in the renal cavity. ${ }^{7}$ A larger dilation may affect calyces. Weiss et al. showed a smaller dilatation of the kidney in the pediatric group with $\mathrm{CV}$ than in a group without $C V .{ }^{8}$ Similar results were shown in the studies on adult patients with hydronephrosis. ${ }^{3}$ In the group of patients with $\mathrm{CV}$, the dilatation grade 1-2 is statistically more often enlarged while in the group without CV, the dilatation is more often grade 3-4 in the SFU (Society of Fetal Urology) scale. In our material, the dilatation of the kidney in the group of patients with CV was not significantly different from the group of patients without $\mathrm{CV}$. In both groups, the median renal pelvic dilatation in the AP dimension was $30 \mathrm{~mm}$. The discrepancy in comparison with the literature may be due to the fact that the cited studies also evaluated the width of the calyx 
cup and in some studies the SFU scale was used. In our material, in each case we assessed the AP dimension of the renal pelvis.

The literature states that Doppler examination is effective in preoperative $\mathrm{CV}$ detection. Veyrac et al. showed CV in ultrasound with Doppler in 25 out of 28 cases of hydronephrosis in children, in which the presence of $\mathrm{CV}$ was later confirmed intraoperatively. ${ }^{9}$ In our material, all the patients before the surgery had a kidney ultrasound examination, but mostly without a Doppler option. Only $10.8 \%$ of them were suspected of having CV. The group of patients in whom we performed urotomography was too small to draw conclusions. In the study by Weiss et al., in $32.5 \%$ of the patients who underwent functional magnetic resonance urography, the radiologists described the presence of $\mathrm{CV}$ in the opposite, healthy kidney. ${ }^{8}$ These studies show that the presence of CV in children is very common, but not every vessel must cause ailments and dilatation of the kidney. Similarly, in adults it is reported that CV occur in about $20 \%$ of healthy people and do not cause any problems. ${ }^{10-13}$ Thus, intraoperative detection of the CV and the assessment of whether this bundle is important for UPJ function is quite subjective; it depends on the surgeon's judgment and largely on his/her experience. Improper assessment and a hasty decision to abandon formal pyeloplasty in favor of vessel dislocation may result in the recurrence of hydronephrosis and the need for reoperation.

The incidence of the CV causing obstruction of the UPJ in children increases with age. ${ }^{14-16}$ Crossing vessels are very rarely noticed in newborns and infants. Similarly, the analyzed material did not show this pathology in any child under 1 year of age. Calisti et al. showed CV in 6 out of $54(11 \%)$ prenatally diagnosed patients with an average age of 3.5 months compared to 12 out of 30 (40\%) symptomatic patients with an average age of 6.4 years. ${ }^{14}$ In the study by Schneider et al., all CV patients were over 2 years of age, with an average age of 10 years (from 2 to 17.3 years). ${ }^{15}$ Maheshwari et al. in a group of 82 patients showed CV in $7(8.5 \%)$ with an average age of 7.12 years (from 4 months to 15 years). ${ }^{16}$ In adults, the proportion of patients with CV is around $39-71 \%$ of all patients with UPJO. ${ }^{3,10-13}$ In the analyzed material, the median age in a child with the presence of CV was 5.5 years in the OPEN group and 6 years in the LAP group, respectively. However, when comparing the age of children with and without the presence of $\mathrm{CV}$, there was no difference - in both groups the median age was 5.75 years.

The aim of this study was to compare the CV detection frequency depending on the surgical technique - laparoscopy with transperitoneal access and the open retroperitoneal approach. Menon et al. described the $\mathrm{CV}$ detection rate in the classical retroperitoneal technique at the level of $5.1 \%$ in a group of 643 patients. ${ }^{7}$ The low number of detected vessels can be explained by the fact that the study qualified patients under 12 years of age, and as we know from the literature, the incidence of additional vessels increases with age. In addition, these authors used the open retroperitoneal technique. In another study, Hacker et al., also in open retroperitoneal pyeloplasty, in patients aged from 6 weeks to 16 years, reported the incidence of vessels in $25 \%$ of the children (28 out of 112 patients). ${ }^{1}$ Assem et al., using the retroperitoneal laparoscopic technique in a group of 23 pediatric patients, demonstrated the presence of CV in 4 of them (17.3\%) intraoperatively. ${ }^{17}$ Simforoosh et al. reported the presence of CV in 9 out of 63 (14.2\%) children operated on using the laparoscopic transperitoneal technique. ${ }^{18}$ The average age of the patients was 5 years. The authors reported 1 case of a patient with CV that were previously overlooked in open pyeloplasty. Data on the detection of additional vessels, reported in the literature, is divergent. This fact could be the result of the significantly different age groups of the patients. In addition, in some reports, the number of patients analyzed is too small to draw important conclusions. There is also a lack of studies comparing the detection rate of vessels depending on 2 different types of operational access in 1 medical center. In available publications, the authors focus on 1 operational access.

In this material, the CV were statistically more frequent in the transperitoneal laparoscopic approach. In the LAP group, the incidence of CV was $34.2 \%$, and in the OPEN group $12.5 \%$, which was statistically significant. Considering the anatomy of the kidney, the additional vascular bundle is located forward in relation to the UPJ. In the transperitoneal approach when preparing UPJ with the presence of $\mathrm{CV}$, it is difficult to omit it. With this anatomy in the open retroperitoneal approach, the vessels are located at the back of the UPJ. In addition, during surgery, often in an older child, where the UPJ is located deep in the surgical field, in order to show it well and prepare, it is necessary to put on the stitches and use traction. With such a maneuver, the UPJ is pulled towards the operator, and the CV remains even deeper in the operating field and it can thus be omitted. In the analyzed material there were 2 cases $(1.4 \%)$ originally operated classically from retroperitoneal approach, where the presence of $\mathrm{CV}$ was not recognized. In reoperation with transperitoneal access using laparoscopy these vessels were detected and cephalad translocation was performed.

\section{Conclusions}

The detection rate of crossing vessels in UPJO is statistically greater in transperitoneal laparoscopic access than in retroperitoneal open pyeloplasty. Distinctive features of patients with the presence of an additional CV are the lack of prenatal diagnosis for hydronephrosis and the presence of pain in the lumbar area. 


\section{ORCID iDs}

Marcin Polok (10 https://orcid.org/0000-0002-1235-563X

Dominika Borselle (1) https://orcid.org/0000-0002-4880-8047

Krystian Toczewski (1D https://orcid.org/0000-0003-4336-2151

Wojciech Apoznański (1) https://orcid.org/0000-0002-0833-7711

Dariusz Patkowski (10) https://orcid.org/0000-0002-4583-5517

\section{References}

1. Hacker HW, Szavay P, Dittmann H, Haber HP, Fuchs J. Pyeloplasty in children: Is there a difference in patients with or without crossing lower pole vessel? Pediatr Surg Int. 2009;25(7):607-611.

2. Kolęda P, Apoznański W, Woźniak Z, et al. Changes in interstitial cell of Cajal-like cells density in congenital ureteropelvic junction obstruction. Int Urol Nephrol. 2012;44(1):7-12.

3. Szydełko T, Apoznański W, Kolęda P, Rusiecki L, Janczak D. Laparoscopic pyeloplasty with cephalad translocation of the crossing vessel - a new approach to the Hellström technique. Wideochir Inne Tech Maloinwazyjne. 2015;10(1):25-29.

4. Wolak P, Golabek T, Obarzanowski M. A complex case of abdominal pain in a patient with pelviureteric junction obstruction. Wideochir Inne Tech Maloinwazyjne. 2014;9(2):273-275.

5. Stephens FD. Ureterovascular hydronephrosis and the aberrant renal vessel. J Urol. 1982;128(5):984-987.

6. Polok M, Apoznański W. Anderson-Hynes pyeloplasty in children - long-term outcomes, how long follow up is necessary? Cent European J Urol. 2017;70(4):434-438.

7. Menon P, Rao KL, Sodhi KS, Bhattacharya A, Saxena AK, Mittal BR Hydronephrosis: Comparison of extrinsic vessel versus intrinsic ureteropelvic junction obstruction groups and a plea against the vascular hitch procedure. J Pediatr Urol. 2015;11(2):80.e1-6.

8. Weiss DA, Kadakia S, Kurzweil R, Srinivasan AK, Darge K, Shukla AR. Detection of crossing vessels in pediatric ureteropelvic junction obstruction: Clinical patterns and imaging findings. J Pediatr Urol. 2015;11(4):173.e1-5.
9. Veyrac C, Baud C, Lopez C, Couture A, Saguintaah M, Averous M. The value of colour Doppler ultrasonography for identification of crossing vessels in children with pelviureteric junction obstruction. Pediatr Radiol. 2003;33(11):745-751.

10. Van Cangh PJ, Wilmart JF, Opsomer RJ, Abi-Aad A, Wese FX, Lorge F. Long-term results and late recurrence after endoureteropyelotomy: A critical analysis of prognostic factors. J Urol. 1994;151(4):934-937.

11. Nakada SY, Wolf JS, Brink JA, et al. Retrospective analysis of the effect of crossing vessels on successful retrograde endopyelotomy outcomes using spiral computerized tomography angiography. J Urol. 1998;159(1):62-65.

12. Sampaio FJ. Vascular anatomy at the ureteropelvic junction. Urol Clin North Am. 1998;25(2):251-258.

13. Zeltser IS, Liu JB, Bagley DH. The incidence of crossing vessels in patients with normal ureteropelvic junction examined with endoluminal ultrasound. J Urol. 2004;172(6 Pt 1):2304-2307.

14. Calisti A, Perrotta ML, Oriolo L, Patti G, Marrocco G, Miele V. Functional outcome after pyeloplasty in children: Impact of the cause of obstruction and of the mode of presentation. Eur Urol. 2003;43(6):706-710.

15. Schneider A, Ferreira CG, Delay C, Lacreuse I, Moog R, Becmeur F. Lower pole vessels in children with pelviureteric junction obstruction: Laparoscopic vascular hitch or dismembered pyeloplasty? J Pediatr Urol. 2013;9(4):419-423.

16. Maheshwari R, Ansari MA, Mandhani A, Srivastava A, Kapoor R. Laparoscopic pyeloplasty in pediatric patients: The SGPGI experience. Indian J Urol. 2010;26(1):36-40.

17. Assem A, Hashad MM, Badawy H. Retroperitonoscopic pyelopexy for pelviureteral junction obstruction with crossing vessel in adolescents: Hellström principle revisited. J Pediatr Urol. 2013;9(4):415-418.

18. Simforoosh N, Javaherforooshzadeh A, Aminsharifi A, Soltani MH, Radfar MH, Kilani H. Laparoscopic management of ureteropelvic junction obstruction in pediatric patients: A new approach to crossing vessels, crossing vein division, and upward transposition of the crossing artery. J Pediatr Urol. 2010;6(2):161-165. 